\title{
Twitter and Public Health (Part 2): Qualitative Analysis of How Individual Health Professionals Outside Organizations Use Microblogging to Promote and Disseminate Health-Related Information
}

Mark Hart", EdD, MALS; Nichole Stetten ", MPH, CPH; Sabrina Islam*, MS; Katherine Pizarro ${ }^{*}$, BHlthSc

Department of Behavioral Science and Community Health, University of Florida, Gainesville, FL, United States

*all authors contributed equally

Corresponding Author:

Mark Hart, EdD, MALS

Department of Behavioral Science and Community Health

University of Florida

1225 Center Drive, HPNP Room 4144

PO Box 100175

Gainesville, FL, 32610

United States

Phone: 13522738545

Fax: 13522736048

Email: kramtrah@phhp.ufl.edu

\begin{abstract}
Background: Twitter is the most popular form of microblogging that is being utilized in public health to engage audiences and to communicate health-related information. Although there is some research showing the various forms of Twitter use in public health, little is known about how individual public health professionals are using their personal Twitter accounts to disseminate health information.

Objective: The purpose of this research was to categorize public health professionals' tweets to evaluate how individual public health professionals are furthering the mission of public health.

Methods: Twitter accounts held by public health professionals were identified, and researchers proceeded to record 6 months' worth of each individual's Twitter feed. During the 6-month period, a total of 15,236 tweets were collected and analyzed using the constant comparison method.

Results: A total of 23 tweet categories among the 15,236 tweets were initially identified. Some of the most common topics among the 23 categories included the following: health nutrition $(n=2008)$, conferences $(n=815)$, Ebola $(n=789)$, Affordable Care Act (ACA)/health care $(n=627)$, and social justice $(n=626)$. Each of these categories were then stratified into one of four themes: (1) informing and educating, (2) monitoring health statuses and trends, (3) social justice, and (4) professional development.

Conclusions: Using Twitter, public health professionals are helping dispel misinformation through education and by translating technical research into lay terms, advocating for health inequalities, and using it as a means to promote professional development.
\end{abstract}

(JMIR Public Health Surveill 2017;3(4):e54) doi: 10.2196/publichealth.6796

\section{KEYWORDS}

Twitter; social media; public health; technology transfer; diffusion of innovation

\section{Introduction}

In a recent paper published in JPHS we described how public health professionals use Twitter for professional development [1]. In the current paper, we describe how public health professionals disseminate health related information using
Twitter. Facebook, Twitter, Instagram, Yik Yak, Snapchat, and YouTube are just a few of the social networking sites (SNSs) that $65 \%$ of adults use daily in the United States [2,3]. Each platform offers a unique way to disseminate information, share opinions, and connect with others around the world in a matter of seconds [2]. Microblogging, a subsection of SNSs, is defined 
as "short, frequent posts" or electronic word of mouth [4-6]. Through microblogging, individuals not only share personal mementos, opinions, political information, and news but also promote products and information, thereby raising awareness for causes or charities [4-6]. Research shows that microblogging is powerful in convincing/rallying other individuals because of immediacy, its far reach to individuals around the world, and is seen as credible because it appears in a print format [6]. As a result of its strong influence, many companies and organizations have adopted microblogging to disseminate information about their company or organization and to promote events and products [4-6]. With such a strong influence and reach, it is important to look at how public health organizations and professionals are using this influence to potentially spread credible knowledge and information to the public as well as a means of professional development.

The most popular form of microblogging, with 313 million active users, occurs through Twitter [7,8]. Twitter allows users to post tweets up to 140 characters or less, as well as links, pictures, and videos after the tweet [7]. The majority of Twitter accounts are public, so any individual can access information on another account simply by following that account [7]. Twitter users are mostly individuals in the age group of 18 to 29 years, who are statistically African American or Hispanic, live in urban areas, and have a higher participation rate than most other SNSs [7]. These users are a challenging population to reach in public health, making Twitter an ideal resource for public health organizations and individuals to focus their efforts [7]. Public health organizations currently use Twitter for (1) informing and education, (2) monitoring health status and trends, (3) surveillance and information in disasters, and (4) professional development [7,9].

Public health organizations disseminate information and education by tweeting about various health-related topics $[7,10]$. Local health departments often tweet information about tobacco cessation resources, events, frequently asked questions about immunizations, and other popular health-related topics. Twitter has also been used as a means to provide sex education and to promote the use of condoms by tweeting facts on sexual health and information about local clinics that provide free condoms [10]. When monitoring health statuses and health trends, also called syndromic surveillance, health departments can search for tweets using keywords or hashtags such as "sick," "flu," "dental pain," and "food poisoning." This allows health departments to identify the geographical area from where these tweets are being posted and to map instances of a potential flu outbreak, food contamination, or an area in need of dental services in real time $[7,11,12]$. Furthermore, health organizations use surveillance and information during disasters by tweeting updates about current local crises such as flooding, fires, hurricanes, and tornadoes [7]. Besides sending information, health organizations can also collect information by searching for geotagged tweets that indicate where emergency relief should focus their attention [7].

Health organizations are also beginning to use Twitter as a source of professional development by tweeting updates while at a conference or an important meeting, thereby allowing other organizations and health professionals to receive updates on the current work and research being conducted [7]. Professional development is also being facilitated via the creation of journal clubs by certain organizations, a Web-based format on Twitter that allows health professionals to tweet questions and responses to the paper as well as the author of the paper to respond to other health professionals in real time [13]. Although public health organizations are adapting to the current social media trends, the current research being conducted focuses primarily on organizations and excludes how individual public health professionals are disseminating health information. This study aims to target these public health professionals' tweets over a 6-month period to evaluate how individuals are furthering the mission of public health.

\section{Methods}

When examining the implementation of new technology, Roger's diffusion of innovation model is commonly used. Although Twitter was founded in 2006 and has gone through the full diffusion of innovation cycle (innovators, early adopters, early majority, late majority, and laggards), the diffusion of innovation model can be used to examine how new ideas and uses of Twitter spread throughout the population or a subpopulation/group. For example, public health organizations did not start using Twitter until more recently because of network filter blocks, but they created new uses for Twitter such as syndromic surveillance $[7,11,12]$. Public health organizations (eg, Centers for Disease Control and Prevention [CDC], local health departments, and National Institutes of Health [NIH]) are farther along the diffusion of innovation cycle, whereas individual public health professionals are just beginning to use Twitter for more than personal usage. These public health professionals can be considered early adopters, as they are expanding beyond the scope of personal usage and using their credentials to identify themselves as an authority and the field and to disseminate public health-related information outside a specific organization. Examining these tweets allows for the identification of information that public health professionals hope to disseminate to colleagues and eventually, to the general population.

\section{Data Collection}

Participants were chosen through Twitter's search function using the terms "public health practitioner," "MPH" (master's in public health), "public health," and "APHA" (American Public Health Association). After individuals were identified as public health professionals, participants were chosen based on a set of inclusion and exclusion criteria. Inclusion criteria were as follows: the individual was a public health professional and had to have a minimum of 300 followers. Exclusion criteria were as follows: the individual could not be a part of an academic institution, and it could not be an organization's Twitter page (eg, CDC, local health departments, and NIH). Overall, 220 public health professionals were chosen to examine their tweets during a 6-month period from October 1, 2014 to March 31, 2015. A total of 15,236 tweets were collected and then analyzed using the constant comparison method. 


\section{Data Analysis}

The constant comparison method was used to analyze the tweets to reduce the data into manageable units and coded information [14-16]. The process began with open coding, which can be defined as "the process of breaking down, examining, comparing, conceptualizing, and categorizing data," where 2 trained researchers (NS and $\mathrm{MH}$ ) open-coded all the tweets and discovered major themes [14-16]. The tweets were then selectively coded into those major themes by the same 2 trained researchers ( $\mathrm{MH}$ and NS; [14-16]). Open coding was done by hand versus using keyword searches through data mining software to take on the full context of the tweets/posts.

\section{Results}

The constant comparison method initially revealed 23 different tweet categories among the 15,236 tweets analyzed, as displayed in Table 1. Each of these categories were then analyzed and coded into four separate themes: informing and education, monitoring health status and trends, social justice, and professional development (Textbox 1).

Table 1. Tweet categories of public health professionals.

\begin{tabular}{|c|c|}
\hline Tweet category & Tweets, $\mathrm{n}$ \\
\hline Non-public health-related & 4032 \\
\hline Health nutrition & 2008 \\
\hline Other & 1885 \\
\hline Conference/Forum/APHA ${ }^{\mathrm{a}}$ & 815 \\
\hline Ebola & 789 \\
\hline Noninfectious diseases & 728 \\
\hline $\mathrm{ACA}^{\mathrm{b}} /$ Health care & 627 \\
\hline Violence/Safety/Social justice & 626 \\
\hline Health law and policy & 567 \\
\hline Technology/Innovation & 553 \\
\hline Environmental health/Factors & 380 \\
\hline Charity/Organizations/NPO ${ }^{\mathrm{c}}$ & 346 \\
\hline Vaccines & 250 \\
\hline Education and literacy & 233 \\
\hline Global famine/Water & 196 \\
\hline Emergency/Emergency preparedness & 176 \\
\hline Global poverty/Homelessness & 170 \\
\hline Infectious diseases & 158 \\
\hline Mental health & 156 \\
\hline HIV $^{\mathrm{d}} / \mathrm{AIDS}^{\mathrm{e}}$ & 143 \\
\hline Smoking/Tobacco/Marijuana & 143 \\
\hline Medications/Drugs and alcohol & 143 \\
\hline Influenza & 112 \\
\hline Total & 15,236 \\
\hline
\end{tabular}

${ }^{a}$ APHA: American Public Health Association.

${ }^{b}$ ACA: Affordable Care Act.

${ }^{\mathrm{c}} \mathrm{NPO}$ : nonprofit organization.

${ }^{\mathrm{d}} \mathrm{HIV}$ : human immunodeficiency virus.

${ }^{\mathrm{e}}$ AIDS: acquired immunodeficiency syndrome. 
Textbox 1. Tweet themes of public health professionals and underlying categories.

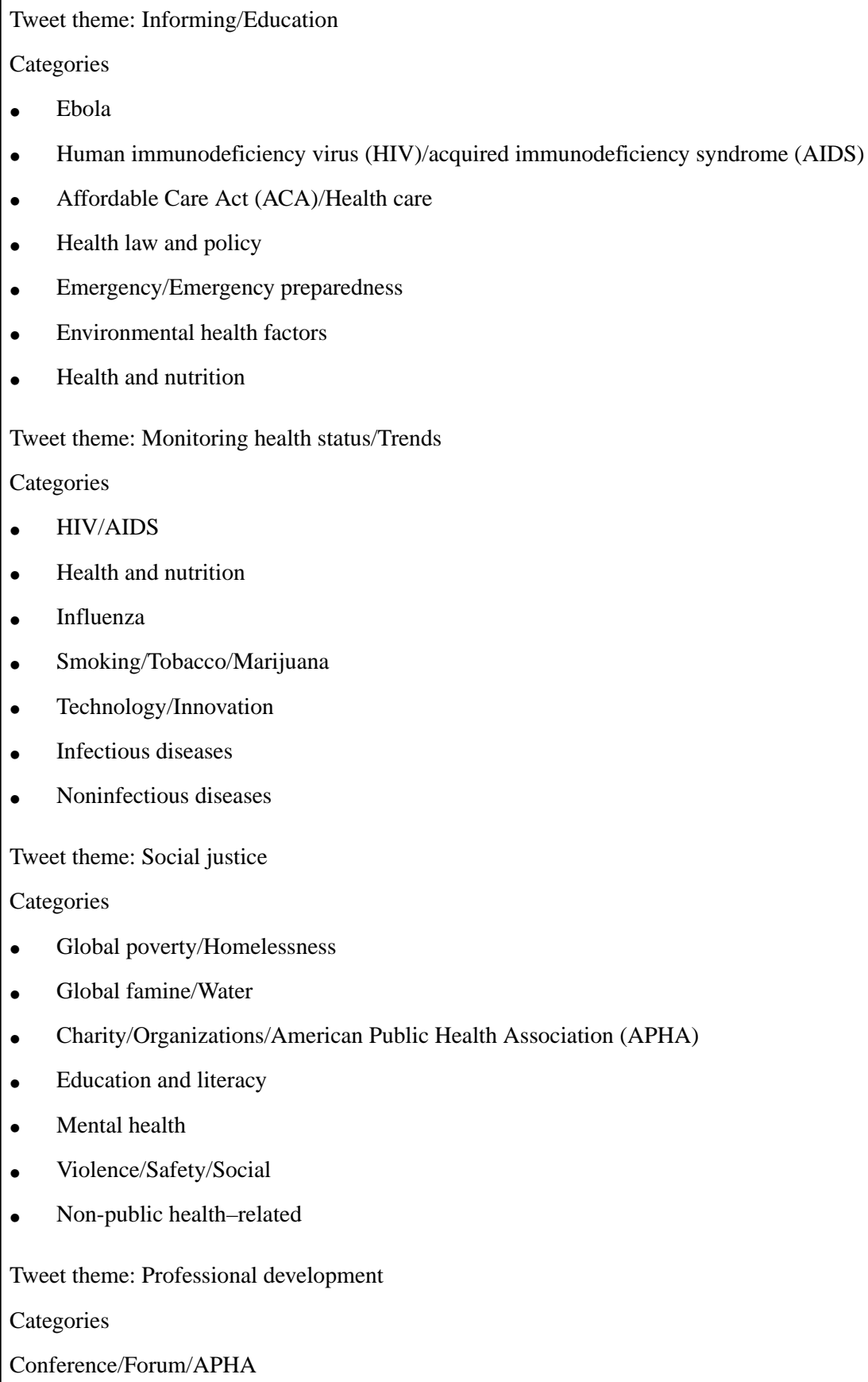

\section{Informing and Education}

Informing and education tweets centered around informing and educating the public on various aspects and updates in public health. Within the theme, there were seven major topic areas covered: Ebola; human immunodeficiency virus (HIV)/acquired immunodeficiency syndrome (AIDS); Affordable Care Act (ACA)/health care; health law and policy; emergency/emergency preparedness; environmental health factors; and health and nutrition (Textbox 1). During the 6-month period of tweets collected, panic about Ebola was prevalent, and many public health professionals tweeted information to dispel panic and myths (see Figure 1).

Another area where public health professionals tweeted information to dispel misinformation was about the ACA (see Figure 2).

Although social media has drastically changed the way of communication, it has also created a way to spread misinformation quickly. As public health professionals have the credentials/authority tied with their Twitter accounts, they can dispel misinformation as well as spread other important health information to the public at a rapid rate. 
Figure 1. Public health professional dispels panic and myths during Ebola panic.

\section{Ebola virus disease is not airborne infection. Airborne spread among humans, inhalation of infectious dose of virus frm small dried droplets}

Figure 2. Public health professional dispels misinformation about the Affordable Care Act.

CBO \#ACA will cost the government $\$ 142$ billion less in next 10 years than last year's report. nytimes.com/2015/03/10/ups...

[C. The New York Times

More Good News on the Deficit, This Time Because of Private Insurance...

Federal budget forecasters lowered estimates of what the

government will spend on health insurance premiums, months after doing the same for Medicare.

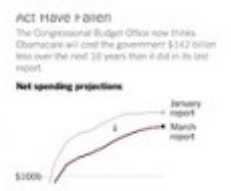

View on web

Figure 3. Public health professional disseminates information about flu epidemic.

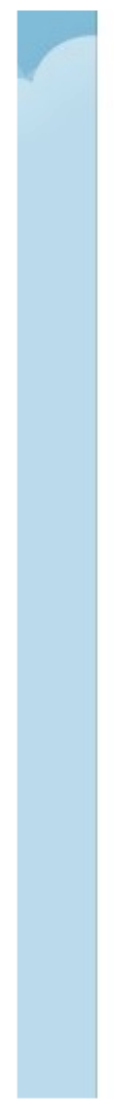

\section{With 15 Children Dead, CDC Declares Flu Epidemic - ABC News abcn.ws/1ztM4NI via @ABC \#H3N2 \#Flu \\ 은 ABC News}

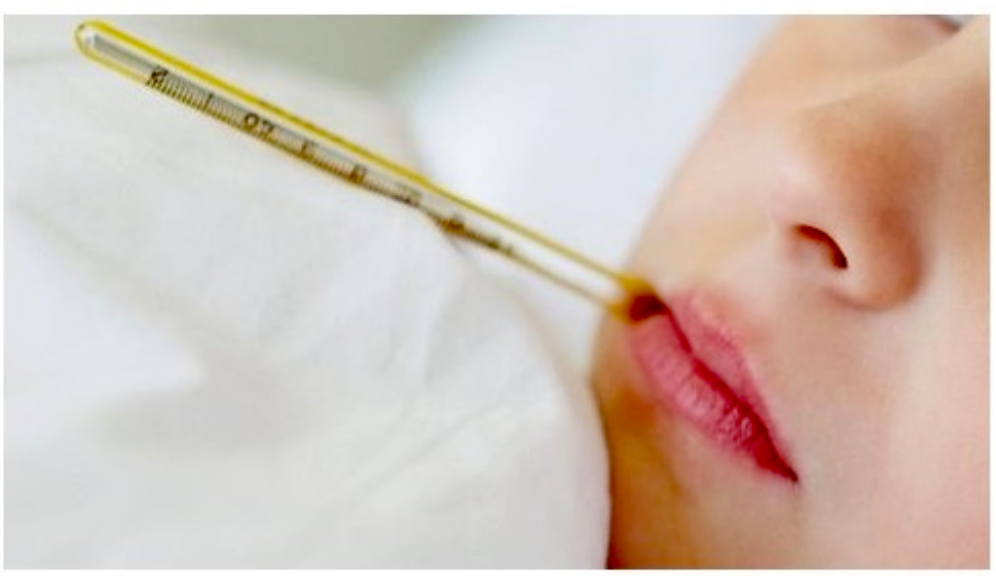

With 15 Children Dead, CDC Declares Flu Epidemic

By \#Liz Neporent @Lizzyfit

The CDC has officially declared this year's flu an epidemic. 
Figure 4. Public health professional shares a study about cigarettes with followers.

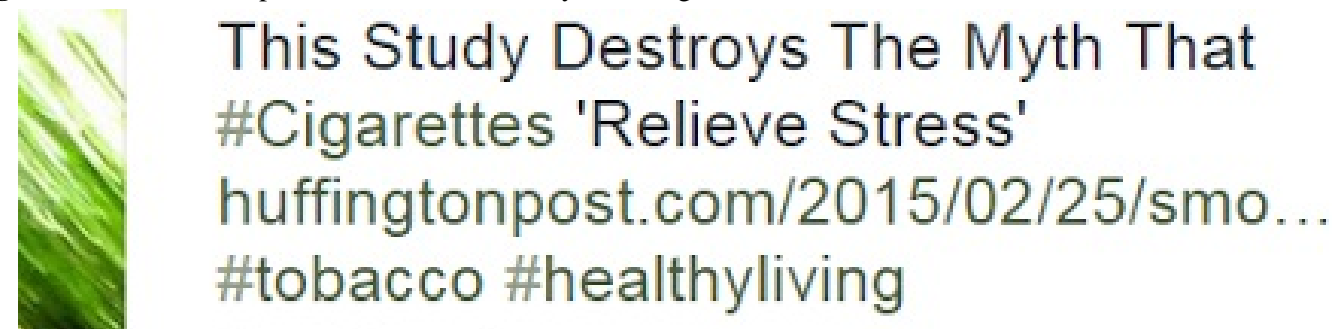

[H] HuffPost Living

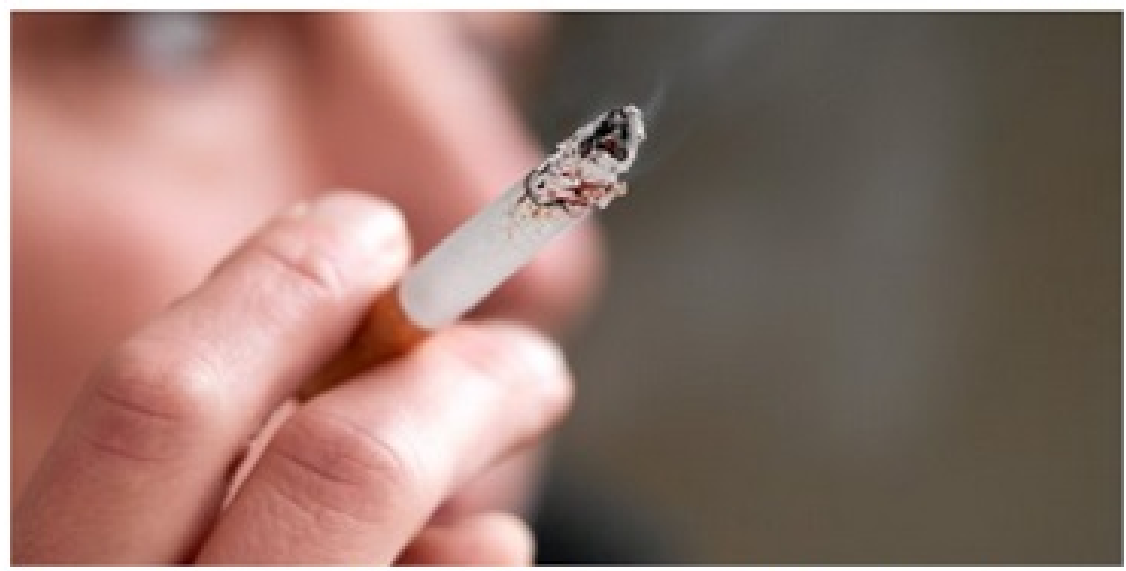

This Study Destroys The Myth That Cigarettes 'Relieve Stress'

If you're looking for another reason to quit, here it is: Cigarettes may be a sign of mental health problems. Contrary to the perception of cigarettes as a stress reliever, smokers are 70 percent...

\section{Monitoring Health Status and Trends}

Tweets identified as monitoring health status and trends were not using surveillance techniques, instead they were informing the public of updates on specific health statuses and trends (see Figures 3 and 4). Within the theme, there were seven major topic areas covered: HIV/AIDS; health and nutrition; influenza; smoking/tobacco/marijuana; technology/innovation; infectious diseases; and noninfectious diseases (Textbox 1).

Through the word limit function in Twitter, public health professionals are forced to condense important information into 140 characters, making these important updates on specific health statuses and trends more relatable to the lay population.

\section{Social Justice}

Social justice tweets focused on raising awareness and support for various public health issues (see Figures 5 and 6). Within the theme, there were seven major topic areas covered: global poverty/homelessness; global famine/water; charity/organizations/APHA; education and literacy; mental health; violence/safety/social justice; and non-public health-related (Textbox 1).

Twitter provides a space for public health professionals to share items they are passionate about, within or outside, their field. This platform also allows them to connect and collaborate with other professionals who are interested in the same social justice issues.

Figure 5. Public health professional speaks about US poverty.

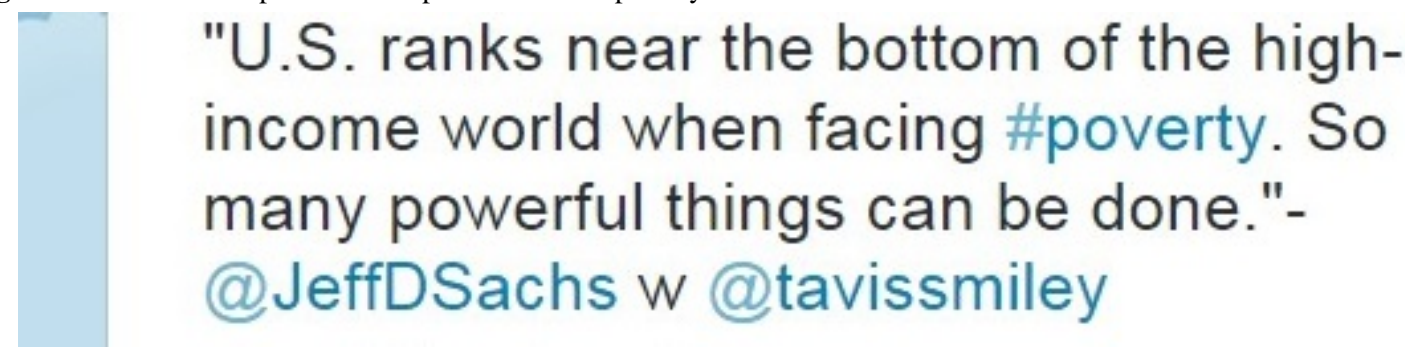


Figure 6. Public health professional shows support for an organization.

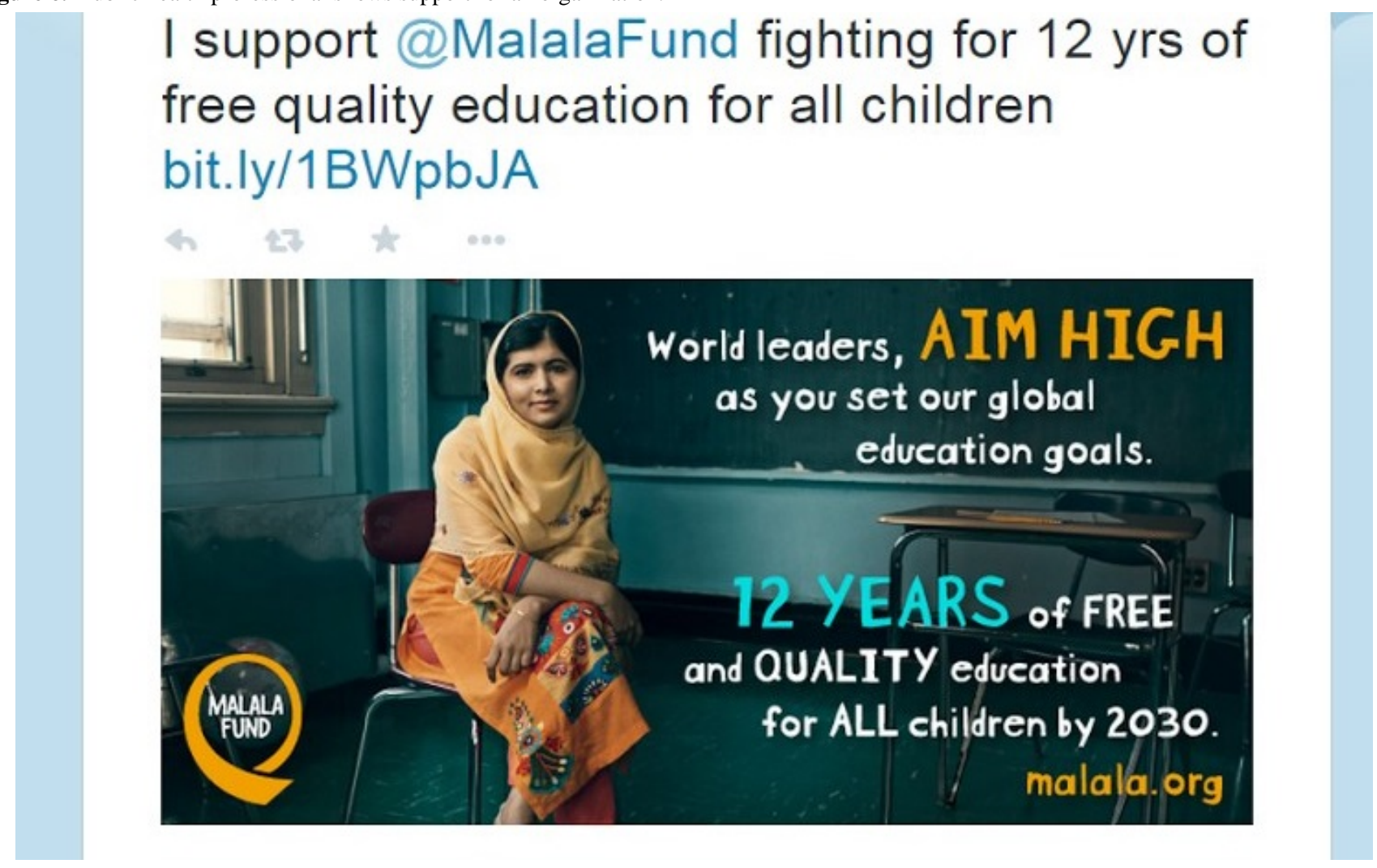

\section{Professional Development}

Professional development occurred when health professionals tweeted new public health information obtained at conferences and forums, as well as with the exchange of sources of scientific literature back and forth between other public health professionals and the general public (see Figures 7 and 8). This particular theme contained only one tweet category: conference/forum/APHA (Textbox 1).

Twitter provides a unique platform for professional development as budget cuts decrease the opportunity to connect and collaborate with other public health professionals.

Figure 7. Public health professional shares his/herconference experience.

\section{Good to see Simon Stevens at @LGAWellbeing@ADPHUKPH conference. Starts with childhood obesity \& half health differences due to smoking.}


Figure 8. Public health professional shares a photo of a conference.

\section{Rain Henderson opens up the @ClintonFdn \#HealthMatters2015 asking "What else can we do together" to improve health?}

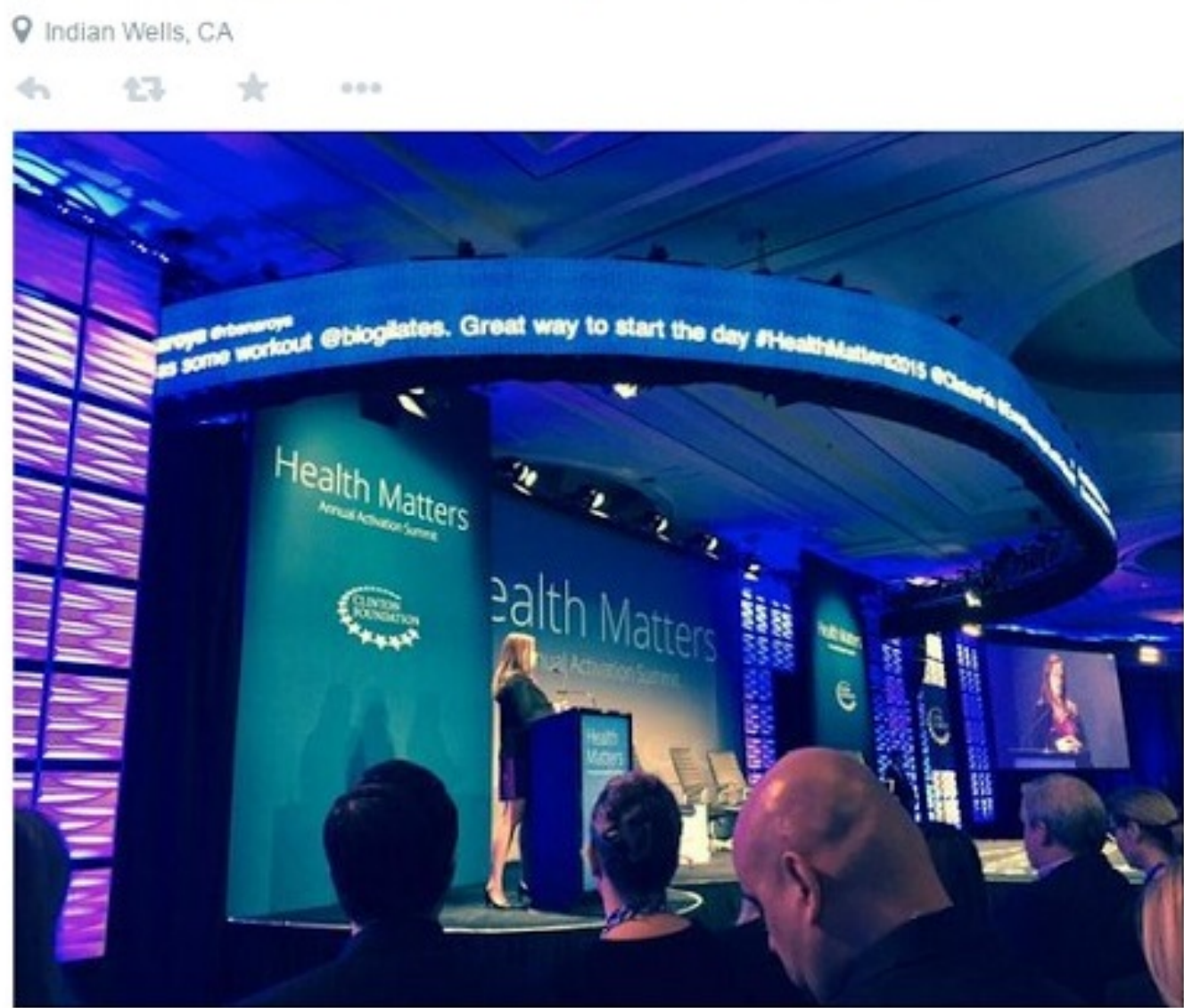

\section{Discussion}

\section{Principal Findings}

Similar to public health organizations, public health professionals are also using Twitter to inform and educate the public. These results are not surprising, as one of the main tenets of public health is to "educate and inform" [7]. This information and education on social media is crucial, as Twitter's main users (aged 18 to 29 years), do not obtain "news" from regular media (newspapers, magazines, and television) but from social media [17]. As social media has become a main resource of knowledge for many, so has misinformation. With the credibility seen in microblogging, it is important for public health professionals with credentials/authority to dispel this misinformation among the public [6]. The results show public health professionals attempting to combat misinformation on Ebola.

Public health organizations use Twitter to monitor health status and trends through syndromic surveillance $[7,11,12]$. However, public health professionals were not using surveillance techniques, they were informing the public about updates on specific health statuses and trends. This also allows public health professionals to take technical research and translate it into 140 characters, or lay terms, for the public to understand and disseminate among their social groups. These tweets may also contain embedded links, which then lead individuals to health department websites or other credible websites where they might not have gone to in the first place [7]. The nature of Twitter also provides the public with a way to ask questions directly, allowing public health professionals to provide information they may not have otherwise [7].

The most visible tenet of public health is the concept of social justice [18]. The concept of social justice stems directly from public health's mission to "protect and promote health of the population as a whole" [18]. Results mirror this founding ethical principle and show that public health professionals are passionate about many health inequalities. Twitter also allows these same professionals a way to connect with other professionals, within and outside public health, who are also advocating for the same issues.

Finally, akin to public health organizations, public health professionals are also using Twitter as a means of professional development. Over the years, many states have seen significant decreases in funding for public health, severely limiting resources available to the public as well as to the public health 
professionals (eg, continuing education and conferences). Twitter provides public health professionals with a unique platform, to still engage with local conferences, as individuals attending tweet about sessions while they are occurring. Twitter also provides a way for public health professionals to connect and collaborate with other public health professionals in real time, despite being limited in funding for travel.

\section{Limitations}

The scope of the tweets examined was during a 6-month window and was limited to that specific time frame. Although limited throughout the 6 months, the tweets reached saturation before 6 months, ensuring that tweets collected were representative of public health professionals' Twitter activity. A second limitation was that the individuals analyzed only had to have a minimum of 300 followers. Although this is a small number of followers, because public health professionals are early adopters, they will not have a large following yet. The final limitation was that the category "non-public health-related" was the most common tweet category. Looking at the categories as a whole makes it appear that public health professionals are not talking about public health the majority of the time, but when one looks at the tweets (see Table 1) as two categories-non-public health and public health $-11,204$ tweets were on various public health topics, and only 4032 were non-public health-related.

\section{Conclusions}

For more adoption to occur among public health professionals, public health organizations should consider removing social media filters, specifically from Twitter. The removal of social media filters would eliminate the barrier of public health professionals only being able to tweet during after work hours, thereby encouraging increased adoption of the social media platform among public health professionals as well as enabling them to rapidly spread critical health information to the public as it occurs "in real time." Unlike the majority of health organizations, public health professionals' individual Twitter accounts outside organizations are not monitored by the government, and they are able to disseminate important information to colleagues and the lay population, such as how climate change affects public health, that organizations may not be able to disseminate, despite how critical that information is to the overall public health in the United States.

\section{Conflicts of Interest}

None declared.

\section{References}

1. Hart M, Stetten NE, Islam S, Pizarro K. Twitter and Public Health (Part 1): How Individual Public Health Professionals Use Twitter for Professional Development. JMIR Public Health Surveill 2017 Sep 20;3(3):e60 [FREE Full text] [doi: 10.2196/publichealth.6795] [Medline: 28931499]

2. Pew Internet. 2017. Social Media Fact Sheet URL: http://www.pewinternet.org/fact-sheet/social-media/[WebCite Cache ID 612EoOhdd]

3. Perrin A. Pew Internet. 2015. Social Media Usage: 2005-2015 URL: http://www.pewinternet.org/2015/10/08/ social-networking-usage-2005-2015/[WebCite Cache ID 615SIQ00P]

4. Java A, Song X, Finin T, Tseng B. Why we twitter: understanding microblogging usage and communities. In: Proceedings of the 9th WebKDD and 1st SNA-KDD 2007 workshop on Web mining and social network analysis. 2007 Presented at: WebKDD/SNA-KDD '07; 2007 Aug 12; San Jose, CA p. 56-65. [doi: 10.1145/1348549.1348556]

5. Veltri GA. Microblogging and nanotweets: Nanotechnology on Twitter. Public Underst Sci 2013 Oct;22(7):832-849. [doi: 10.1177/0963662512463510] [Medline: 23825265]

6. Jansen BJ, Zhang M, Sobel K, Chowdury A. Twitter power: Tweets as electronic word of mouth. J Assoc Inf Sci Tec 2009 Nov;60(11):2169-2188. [doi: 10.1002/asi.21149]

7. Bartlett C, Wurtz R. Twitter and public health. J Public Health Manag Pract 2015;21(4):375-383. [doi: 10.1097/PHH.0000000000000041] [Medline: 24356087]

8. Twitter. 2016. Company Facts URL: https://about.twitter.com/company [accessed 2016-10-05] [WebCite Cache ID 612ERcRNA]

9. Roberts MJ, Perera M, Lawrentschuk N, Romanic D, Papa N, Bolton D. Globalization of continuing professional development by journal clubs via microblogging: a systematic review. J Med Internet Res 2015 Apr 23;17(4):e103 [FREE Full text] [doi: 10.2196/jmir.4194] [Medline: 25908092]

10. Lefebvre C. Integrating cell phones and mobile technologies into public health practice: a social marketing perspective. Health Promot Pract 2009 Oct;10(4):490-494. [doi: 10.1177/1524839909342849] [Medline: 19809002]

11. Denecke K, Krieck M, Otrusina L, Smrz P, Dolog P, Nejdl W, et al. How to exploit twitter for public health monitoring? Methods Inf Med 2013;52(4):326-339. [doi: 10.3414/ME12-02-0010] [Medline: 23877537]

12. Heaivilin N, Gerbert B, Page JE, Gibbs JL. Public health surveillance of dental pain via Twitter. J Dent Res 2011 Sep;90(9):1047-1051 [FREE Full text] [doi: 10.1177/0022034511415273] [Medline: 21768306]

13. Rogers EM. Diffusion of Innovations. 5th Edition. New York: Simon and Schuster; 2003.

14. Glaser BG, Strauss AL. The discovery of grounded theory: strategies for qualitative research. New York: Aldine Transaction; 1967.

15. Patton MQ. Qualitative Evaluation and Research Methods. USA: SAGE Publications; 2002. 
16. Strauss A, Corbin JM. Basics of Qualitative Research: Techniques and Procedures for Developing Grounded Theory. Newbury Park, CA: SAGE Publications; 1990.

17. Marchi R. With Facebook, Blogs, and Fake News, teens reject journalistic “objectivity". J Commun Inq 2012 Oct 03;36(3):246-262. [doi: 10.1177/0196859912458700]

18. Buchanan DR. Autonomy, paternalism, and justice: ethical priorities in public health. Am J Public Health 2008 Jan;98(1):15-21. [doi: 10.2105/AJPH.2007.110361] [Medline: 18048780]

\section{Abbreviations}

ACA: Affordable Care Act

AIDS: acquired immunodeficiency syndrome

APHA: American Public Health Association

CDC: Centers for Disease Control and Prevention

HIV: human immunodeficiency virus

MPH: master's in public health

NIH: National Institutes of Health

SNS: social networking site

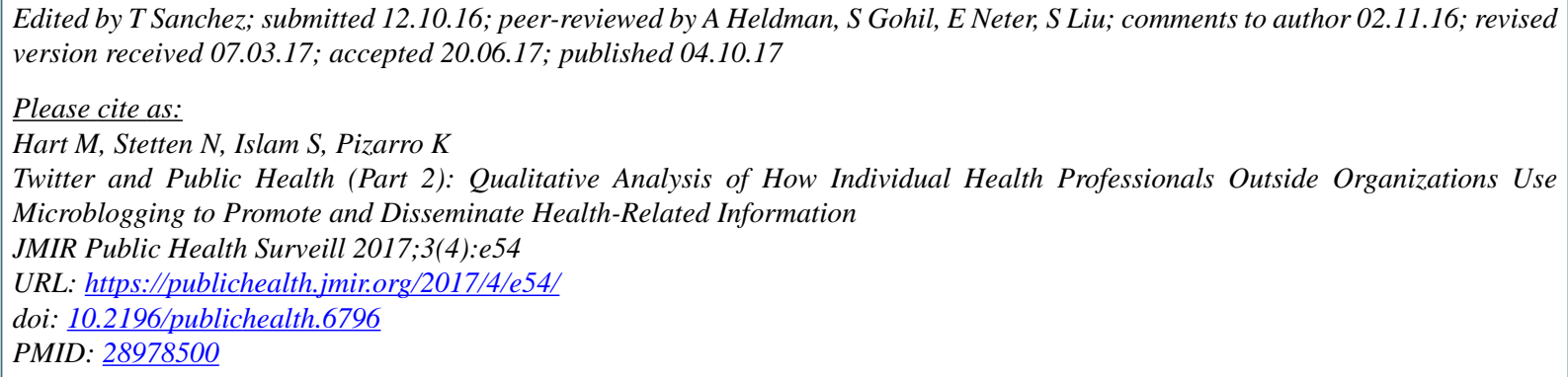

CMark Hart, Nichole Stetten, Sabrina Islam, Katherine Pizarro. Originally published in JMIR Public Health and Surveillance (http://publichealth.jmir.org), 04.10.2017. This is an open-access article distributed under the terms of the Creative Commons Attribution License (https://creativecommons.org/licenses/by/4.0/), which permits unrestricted use, distribution, and reproduction in any medium, provided the original work, first published in JMIR Public Health and Surveillance, is properly cited. The complete bibliographic information, a link to the original publication on http://publichealth.jmir.org, as well as this copyright and license information must be included. 